\title{
Research Report of Internationalization of Graduate Education-CTake Beijing Institute of Technology as an Example
}

\section{Gao-lan Hou ", Zhou Zou}

School of Management and Economics, Beijing Institute of Technology, Beijing, China

\section{Email address:}

hougaolan@bit.edu.cn (Gao-lan Hou), z_zwsc@126.com (Zhou Zou)

${ }^{*}$ Corresponding author

\section{To cite this article:}

Gao-lan Hou, Zhou Zou. Research Report of Internationalization of Graduate Education_— Take Beijing Institute of Technology as an Example. Science Innovation. Vol. 4, No. 6, 2016, pp. 253-258. doi: 10.11648/j.si.20160406.12

Received: October 9, 2016; Accepted: November 22, 2016; Published: December 1, 2016

Abstract: Internationalization of High Education is an inevitable trend. Graduate Education is an important link. The research report focuses on the current situation and problem in internationalization of graduate education in the field of economics and management by taking Beijing Institute of Technology as an example so as to give some advises.

Keywords: Graduate Students Major in Economics and Management, Internationalization of Education, Situation and Problem

\section{经管类研究生教育国际化调查报告一一以北京理工大学为例}

侯高岗 ${ }^{*}$ 邹周

管理与经济学院, 北京理工大学, 北京, 中国

邮箱

hougaolan@bit. edu. cn（侯高岗），z_zwsc@126. com（邹周）

摘要: 高等教育国际化是高校发展的一个必然趋势。研究生教育作为高等教育链条中的最顶端, 是一个十分重要的环 节。本项研究报告通过问卷调查及访谈等方法, 以北京理工大学为例, 着重研究经管类研究生教育国际化的现状以及 存在的问题, 为我国经管类学院研究生教育国际化提出一些政策建议。

关键词: 经管类研究生, 教育国际化, 问题及建议

\section{1. 引言}

在研究生教育国际化这个问题上, 中国的起步远落后 于欧美日等发达国家。19世纪中后期, 我国才从真正意义 上开始进行正式的对外交流，而之前一直处于闭关锁国的 状态, 教育的开放和国际交流极度嘈乏。这也导致我国研 究生教育从建立之初就必然是一个不断向别国学习和模
仿的模式, 从早期模仿日本模式确立研究生制度, 到对苏 联模式的照搬复制, 再到对德美英等发达国家的借鉴效仿, 我国研究生教育国际化的发展就像一部不断学习和自我 改进的历史。

现阶段我国研究生教育国际化处于快速发展时期, 有 关研究生教育国际化的文献从2001年以来开始增多, 可以 将有关研究分为五个方面, 一是关于内涵的研究, 二是评 
价指标体系, 三是现状与问题, 四是比较研究, 五是实施 策略研究。这五方面的研究大多是从国家宏观层面进行的 比较宽泛的描述和讨论, 而立足于高校某一专业视角开展 调查研究, 从而发现高校研究生教育国际化推进过程中的 问题, 进行相关讨论并给出政策建议的研究还比较少。研 究生教育国际化的实行者和推动者的主体是高等院校, 从 高校视角进行的相关研究非常重要, 这对加快推进研究生 教育国际化健康发展具有重要意义。

研究生教育国际化不仅是我国高等教育适应全球形 势的一种需要, 也是衡量我国高等教育水平的一个重要标 准。自进入新世纪以来, 随着我国市场经济的不断深化, 对具有一定学术基础的经管类研究生的需求持续增加, 各 高校陆续增设了经管类硕士生和博士生培养方向。经管专 业研究生不同于其他专业的研究生, 由于大多数经管类课 程是从西方国家引进的, 因而经管专业研究生教育具有更 强的开放性和国际化的特征, 经管类研究生教育的国际化 势在必行, 也有必要先行一步, 从而给其他专业的研究生 教育国际化提供经验与借鉴。本文立足作者所在学院一一 北京理工大学管理与经济学院, 通过问卷和访谈调研, 主 要从研究生教学课程设置与教材选取、研究生的国际化意 识, 以及来华外国留学生现状几个方面, 分析了研究生教 育国际化现状及存在问题, 提出了相关政策建议。

\section{2. 研究方法}

为了充分了解我校经管类研究生教育国际化的情况, 本次调查主要采用调研问卷与访谈相结合的方法。针对经
管类研究生这一群体设置了调研问卷, 对学院的教师设计 了访谈提纲, 其中问卷将被调查者分为学术型硕士研究生、 专业型硕士研究生以及博士研究生三类, 而访谈提纲将教 师分为学院领导层以及授课教师两个层次。本次调查共发 放问卷 125 份, 回收的有效问卷为 120 份; 访谈的领导层教 师共 2 人，普通授课教师共 3 人。在问卷及访谈提纲的设计 上, 参考了罗英姿关于高校研究生教育国际化评价指标体 系以及其他一些评价标准, 同时就经管类研究生这个特定 的研究群体对问卷和提纲进行了修改, 加入了符合经管类 研究生的一些调查问题。现简要对问卷及访谈结果加以统 计分析。将调查问卷细分为三类, 是考虑到学术硕士、专 业硕士及博士三类研究生在具体的培养模式与发展方向 上有所不同; 而将访谈对象分为针对学院领导层及授课教 师两类, 是因为处于不同层面的教师能够解答的问题是不 同的, 进行必要的区分有利于访谈提纲的设计, 从而可获 得从学院领导、授课教师和研究生导师三个视角的有关研 究生教育国际化的相关情况、政策观点以及个人观点。

\section{3. 调研内容}

\section{1. 课程设置与教材选取}

对学生通过问卷调研，询问全英文授课、中英双语授 课、双学位课程 (具有国外学位) 和使用国外原版教材及 使用国外译本教材的课程门数, 如下面表 $1^{\sim}$ 表 4 所示; 对 教师则是通过访谈的方式, 了解教师授课方式及相关感受 与看法。

表1 全英授课门数及比例。

\begin{tabular}{lllllll}
\hline 全英授课门数 & 0 & 1 & 2 & 3 & 5 & 4 \\
\hline 学硕 & $72.9 \%$ & $20.8 \%$ & $6.3 \%$ & $0 \%$ & $0 \%$ & $0 \%$ \\
专硕 & $59.6 \%$ & $17.0 \%$ & $17.0 \%$ & $2.1 \%$ & $2.1 \%$ & $0 \%$ \\
博士 & $48.0 \%$ & $28.0 \%$ & $8.0 \%$ & $16.0 \%$ & $0 \%$ & $0 \%$ \\
\hline
\end{tabular}

表2 双语授课门数及比例。

\begin{tabular}{llllllll}
\hline 双语授课门数 & 0 & 1 & 2 & 3 & 4 & 5 & $>5$ \\
\hline 学硕 & $60.4 \%$ & $20.8 \%$ & $12.5 \%$ & $6.3 \%$ & $0 \%$ & $0 \%$ & $0 \%$ \\
专硕 & $25.5 \%$ & $27.7 \%$ & $29.8 \%$ & $14.9 \%$ & $2.1 \%$ & $0 \%$ & $0 \%$ \\
博士 & $32.0 \%$ & $36.0 \%$ & $24.0 \%$ & $8.0 \%$ & 0 & $0 \%$ & $0 \%$ \\
\hline
\end{tabular}

表3 使用外文原版教材授课门数及比例。

\begin{tabular}{lllllll}
\hline 外文原版教材授课门数 & 0 & 1 & 2 & 3 & 5 & \\
\hline 学硕 & $83.3 \%$ & $8.3 \%$ & $8.3 \%$ & $0 \%$ & $0 \%$ & $0 \%$ \\
专硕 & $42.2 \%$ & $22.2 \%$ & $22.2 \%$ & $11.1 \%$ & $0 \%$ & $2.2 \%$ \\
博士 & $66.7 \%$ & $16.7 \%$ & $8.3 \%$ & $8.3 \%$ & $0 \%$ & $0 \%$ \\
\hline
\end{tabular}

表4 使用英文译本教材授课门数及比例。

\begin{tabular}{llllllll}
\hline 英文译本授课门数 & 0 & 1 & 2 & 3 & 4 & 5 & $>5$ \\
\hline 学硕 & $39.6 \%$ & $20.8 \%$ & $25.0 \%$ & $8.3 \%$ & $2.1 \%$ & $0 \%$ & $4.2 \%$ \\
专硕 & $27.7 \%$ & $4.3 \%$ & $29.8 \%$ & $19.1 \%$ & $6.4 \%$ & $8.5 \%$ & $2.1 \%$ \\
博士 & $56.0 \%$ & $16.0 \%$ & $20.0 \%$ & $8.0 \%$ & $0 \%$ & $0 \%$ & $0 \%$ \\
\hline
\end{tabular}

根据结果显示, 博士生在全英与双语授课两方面要好 于专硕, 专硕优于学硕（见表1和表2）。在课程中选取全 英教材及英文译本的情况, 专硕好于博士, 博士优于学硕
（见表3和表4）。通过对教师的访谈了解到, 部分教师认 为并不是所有课程都适合英文教学, 而双语授课可以作为 全英授课的一个过渡环节, 但并不适合作为一种正式的授 
课模式长期进行。学院鼓励教师开设英文课程, 但尚未采 取相应的激励措施, 目前主要采取教师自愿原则。教师是 否采用英文授课, 则会考虑学生的英文水平及其专业背景, 但大多数采用中文授课的教师都会在课堂上鼓励学生课 后阅读英文教材或相关文献, 作为中文课程的补充和扩展。 总体来看, 北京理工大学经管类研究生教学中, 全英文与 双语授课的课程门数并不是很多, 原因主要有如下两点:

(1) 学生英文水平参差不齐。在所调研的经管院研 究生中, 英文水平存在差异, 虽然大多数硕士生都通过了 国家英语四级考试, 但并非所有学生都参加并通过了六级 考试, 尤其是英文的听说能力差异较大。一些硕士生的专 业背景与本科时期不同, 对所学的专业知识还需要通过自 学进行弥补。授课教师考虑到一些学生英文基础较差和跨 专业的背景, 认为英文授课并不适宜, 盲目追求国际化可 能收不到预期效果。

（2）教师在英文课程的准备上可能会牵扯较大的精 力。通过访谈我们了解到, 教师除了授课之外还有科研任 务。而英文课程的准备需要比中文备课付出更多的时间和 精力, 在英文授课的准备上不仅仅是简单地把课件、教材 和授课内容都转换成英文, 还需要形成课堂讨论、小组项 目和文献阅读等一整套授课体系, 考虑到学生的接受能力, 加上教师自身沉重的科研任务, 大多数教师不得不放弃英
文授课的打算。另一方面, 一些教师受个人英文能力的限 制, 也会对英文授课退避三舍。接受访谈的教师虽然都拥 有海外学习及交流的背景, 但是大多数教师出国访学的目 的是学术研究和科研交流, 对于国外先进的授课方法及模 式并没有较为深入的了解。相比之下, 北京理工大学在本 科教学上开设有 4 个专业方向的国际班, 明确规定采用全 英文授课, 相应地, 学校教务处设有每年选送优秀教师出 国观摩听课的英文教学培训项目; 但在研究生教学上, 目 前尚未在全校范围内开展类似项目。

此外, 我们在调研中也听到另外一种声音, 那就是强 烈反对面向硕士生开设全英文课程, 一方面英文备课会牵 扯教师过多精力, 由于授课教师英文能力有限, 必然导致 教师减少授课内容, 加上学生英文能力也不足, 降低听课 效果，导致消耗大量人力物力的同时，收不到良好的授课 效果。

\section{2. 学院研究生的国际化意识}

通过在研究生的调研问卷中设计有关国际交流项目 等问题来考量学院研究生的国际化意识, 如下面表 $5^{\sim}$ 表 8 所示。

表5 关于 “会关注和参加学院和学校召开的国际的学术研讨会” 认可度的调查结果。

\begin{tabular}{llllll}
\hline 会关注和参加学院和学校召开的国际性的学术研讨会 & 非常不符合 & 比较不符合 & 不好确定 & 比较符合 & 非常符合 \\
\hline 学硕 & $4.2 \%$ & $31.3 \%$ & $18.8 \%$ & $35.4 \%$ & $10.4 \%$ \\
专硕 & $11.1 \%$ & $15.6 \%$ & $37.8 \%$ & $33.3 \%$ & $2.2 \%$ \\
博士 & $0 \%$ & $36.0 \%$ & $16.0 \%$ & $40.0 \%$ & $8.0 \%$ \\
\hline
\end{tabular}

表6 对 “学院和学校有较多的出国交流项目” 的认可度的调查结果。

\begin{tabular}{lllll}
\hline 学院和学校有较多的出国交流项目 & 非常不符合 & 比较不符合 & 不好确定 & 比较符合 \\
\hline 学硕 & $2.1 \%$ & $31.3 \%$ & $22.9 \%$ & $37.5 \%$ \\
专硕 & $8.5 \%$ & $17.0 \%$ & $29.8 \%$ & $3 \%$ \\
博士 & $4.0 \%$ & $20.0 \%$ & $32.0 \%$ & $38.3 \%$ \\
\hline
\end{tabular}

表7 关于 “对学院和学校的出国交流项目的具体内容非常了解” 的认可度的调查结果。

\begin{tabular}{llllll}
\hline 对学院和学校的出国交流项目的具体内容非常了解 & 非常不符合 & 比较不符合 & 不好确定 & 比较符合 & 非常符合 \\
\hline 学硕 & $8.3 \%$ & $52.1 \%$ & $29.2 \%$ & $8.3 \%$ & $2.1 \%$ \\
专硕 & $17.4 \%$ & $34.8 \%$ & $30.4 \%$ & $17.4 \%$ & $0 \%$ \\
博士 & $17.4 \%$ & $34.8 \%$ & $30.4 \%$ & $17.4 \%$ & $0 \%$ \\
\hline
\end{tabular}

表8 对 “有合适的机会您会主动去申请参加有关的交流项目或是学术研讨会” 认可度的调查结果。

\begin{tabular}{|c|c|c|c|c|c|}
\hline 会主动去申请参加有关的出国交流项目或是学术研讨会 & 非常不符合 & 比较不符合 & 不好确定 & 比较符合 & 非常符合 \\
\hline 学硕 & $4.2 \%$ & $8.3 \%$ & $20.8 \%$ & $52.1 \%$ & $4.3 \%$ \\
\hline 专硕 & $6.4 \%$ & $21.3 \%$ & $21.3 \%$ & $46.8 \%$ & $4.3 \%$ \\
\hline 博士 & $0 \%$ & $32.0 \%$ & $28.0 \%$ & $32.0 \%$ & $8.0 \%$ \\
\hline
\end{tabular}

针对学校召开的国际性学术研讨会, 学生关注和参加 的程度超过半数（见表5）。而针对学院出国交流项目及 对于项目了解程度的问题上, 近半数研究生表示学院有较 多的出国交流项目（见表6）, 但相对来看, 研究生对这 些项目的了解程度偏低（表7）。在对出国交流项目了解 程度相对较低的情况下, 超半数的学生表示会主动参加出 国交流项目或是学术研讨会（见表8）。分析其原因, 我 们认为, 可能是由于学校或学院的国际交流项目和学术研 讨会, 对于本校研究生来说具有 “近水楼台先得月” 的优
势, 在时间和金钱上都是最为经济的, 研究生对本校和所 在学院交流项目的关注度更高也是自然而然的; 而且, 一 些导师在相关研究领域与国外教授或专家存在合作关系, 在学院鼓励教师介绍国外专家来院开展讲座的政策激励 下, 一些导师会设法邀请国外专家来院讲学，一般会强烈 建议自己的学生参加讲座, 从而拓展学生视野, 直接提升 了研究生参加这些项目和活动的积极性。研究生国际化意 识的增强, 也促使他们为了自身以后能更好地发展, 会有 一定的积极性去主动关注学院的交流项目或是学术活动。 
在参与出国交流项目方面, 学生虽然也表现出一定的 积极性, 但绝大多数研究生并不十分了解项目的具体内容, 在参与出国交流项目方面表现出一定的盲目性。通过本项 目组成员中的一位研究生与周围同学的接触了解到的情 况来看, 部分研究生在选择参加交流项目时, 只是单纯为 了具有海外交流的背景, 对于海外项目的选择, 仅仅主要 考量自己是否符合参加这些项目的条件, 从而易于获得批 准, 而对项目的具体内容, 并没有进行仔细地考察和了解。 部分交流项目并不是全额公费资助, 对于这些项目, 一些 在读研究生可能会因为经济因素而放弃申请。从硕士生与 博士生的比较来看, 在出国交流项目的参与度上, 学硕与 专硕表现出了较高的积极性, 好于博士（见表8）。这可 能是由于博士生要承担比硕士生更多的科研任务, 这会使 博士生没有较长的连续时间段去参加出国交流项目, 导致 博士生对于海外交流项目参加的积极性低于硕士生。但是 对于学校和学院召开的国际学术研讨会的关注度, 总体来 看, 博士生的关注度较高, 也表明了博士生更为积极的科 研态度。

通过情况调研和原因分析, 说明无论是硕士生还是博 士生, 已经具备一定的国际化意识, 他们能够积极参与学 校和学院的国际交流项目, 但在参与出国交流项目的积极 性方面会在一定程度上受到时间和金钱等因素的影响，对 于一些能够参加的全额资助的出国交流项目的具体内容 的了解相对来说较差。

\section{3. 来华外国留学生现状}

由于北京理工大学经管专业的留学生人数不是很多, 总共只有十几名, 不便使用问卷的方式对留学生进行调研, 所以我们找到相关工作人员, 通过电话联系到 5 位经管专 业的留学生, 对他们进行了访谈。由于与他们进行中文交 流很困难, 所以访谈采用英语进行。这 5 位学生中, 有 2 位男生来自韩国, 2 位女生来自哈萨克斯坦, 还有 1 位男生 来自白俄罗斯。他们中4位都是通过中国国家留学基金委 的奖学金到我校来留学的。2015年的资助额度是3000元/ 月, 之前是 1700 元/月。只有一位是完全自费形式来我校 留学的。这5位被访谈的留学生到北京理工大学就读的形 式都是有学位的培养, 学制为两年, 而不是参与交换项目 等其他方式。他们选择到中国留学的原因有三个方面, 一 是可以学习汉语; 二是希望提升自己的知识水平; 三是因 为中国是当前世界经济发展的中心。关于语言问题, 我们 了解到, 他们一周有 $3 门$ 门课程是汉语课, 一门是中文讲授 的中国历史, 另外两门是中文讲授的汉语学习课程。他们 反映中国历史对于汉语基础几乎为零的他们来说太难, 基 本上听不懂, 而汉语学习课课时太少, 想要快速掌握汉语 难度很大。在日常生活中, 他们更多地是使用英语 (与中 国本地人交流时）和本国母语（与本国朋友相处时）, 中 文只会简单的词汇。从学习方面来看, 他们倾向于选择全 英文或双语授课的课程, 但是经管学院全英文课程不是很 多, 留学生只能选择中文课程, 他们表示听不懂, 希望能 开设更多英文讲授的课程。另外, 留学生表示也不理解为 什么与他们沟通的管理人员不能使用英语。留学生与导师 沟通交流的频率约为一年5次或更少, 导师也没有让留学
生承担毕业论文之外的科研项目。关于毕业规划的问题, 有4位留学生表示打算回国后寻找与中国有关联的企业去 工作, 有1位学生表示可能考虑毕业后留在中国工作。对 于校方和学院对留学生管理方面的问题, 5位留学生吐槽 不能自行选择舍友, 夫妻留学生也不允许住在一起, 而且 留学生宿舍一个房间的人数从 2015 年的 5 人, 增加到今年 的每个房间 10 人。上述规定和住宿情况让他们觉得很不适 应。在对教师的访谈中, 我们发现不少导师认为, 指导外 国留学生是 “费力不讨好” 的苦差, 因为增加自己工作量 的同时, 学生又不能为自己分担任何科研工作, 于是, 招 收外国留学生的动力普遍不足。我们分析这种情况主要是 由于外国留学生的生源质量不高造成的。

在当前国内高校暂时难以吸引到高水平外国留学生 的条件下, 为了推动本校的国际化, 应不应该招收质量不 高的外国留学生, 成为我们课题组关心的一个问题。针对 这一问题, 我们特地对人民大学商学院的教师进行了访谈, 我们了解到, 人大商学院外国留学生人数很少, 主要原因 就是由于学院不愿降低标准吸收质量不高的外国留学生, 高水平留学生招不到就宁肯不招, 而不会为了国际化而国 际化, 招来不但不能为学院做出高质量的科研成果、反而 成为授课教师和导师负担的留学生, 对形成全院高标准严 要求的学风造成不良影响。

\section{4. 相关建议}

通过对北京理工大学经管类研究生就研究生教育国 际化问题, 对学生进行的问卷调研和对教师开展的访谈所 获得的信息来看, 反映了本校经管类研究生教育国际化进 程中存在的一些问题, 这些问题也是国内高校经管专业研 究生教育国际化过程中存在的共性问题, 现总结如下, 并 对加快推进研究生教育国际化进程和提升国际化质量, 提 出相关建议。

(1) 加快建设研究生全英文学科、建设国际化课程体系。

我们在本校的调研中发现, 北京理工大学本科设有全 英文教学的国际班, 拥有较为系统的全英文教学课程体系, 但在研究生层面目前尚未建立全英文学科和国际化课程 体系。比较而言, 研究生教育由于其以培养学生研究能力 为主要目标, 对学生的英文能力以及与学科的国际前沿接 轨提出更高的要求, 因此也更应该开设全英文学科和构建 国际化课程体系。实际上, 我们注意到大多数研究生课程 授课教师已在教学内容中加入一定比例的国际前沿热点 问题, 也十分注意引导学生加强对英文教材和相关英文文 献的阅读和学习, 以便使学生掌握相关领域的前沿知识。 但是从全校或是学院层面来看, 尚未在全体研究生教育层 面形成系统的全英文授课体系。研究生教育国际化程度滞 后的局面函需改变, 通过借鉴本科生国际班的创建方法, 对学生进行一定篎选, 挑选那些英语水平高、专业背景好、 并具有学习全英文课程意愿的学生, 开设研究生层次的国 际班, 集中优势资源建设全英文研究生学科和国际化课程 体系。避免对学生和课程不加区分的、随意性的 “一刀切” 式全英文授课模式。为解决教师英文授课积极性不高的问 
题, 应在政策上制定激励措施, 出台类似的资助教师出国 观摩英文授课的培训项目。

此外, 我们也要认识到, 英文课程的设置应全面考虑 学生情况和课程特点是否适合英文授课, 不能简单地以为 使用英文授课就是实现教育的国际化了, 因为英文只是交 流沟通的工具, 英文的运用有利于国际化过程中的交流, 但在教育国际化中重要的是掌握国际前沿领域的知识和思 想, 如果能用母语摄取这些知识和思想也未尝不可。但是, 在语言能力没有问题的条件下，使用英文原文肯定是更直 接、更具时效性的方式。我们强调的是应从课程内容及教 学方法等各方面, 整体看待教学是否跟上了国际化教育的 步伐。

(2)增加更多经济省时的国际交流项目，制定出国交流 项目考核机制。

通过问卷调研, 我们发现大多数研究生对于学校或学 院开展的国际交流项目和学术研讨会, 能够积极关注并主 动参与, 表明研究生的国际化意识有所增强。但是我们也 发现, 对于出国交流项目, 不少学生由于经济方面的原因 而放弃参加; 同时, 一些参加了出国交流项目的研究生只 是为了增加海外经历, 而不是出于科研目的, 参与项目的 具体内容与自身研究方向的相关性不高, 呈现出在参与出 国交流项目中, 经济因素和是否容易获得邀请函因素超过 科研目标。针对上述情况, 一方面学校及学院应进一步增 加更多本校或学院推出的国际研讨会等交流项目, 为研究 生提供更多经济省时的国际交流机会; 另一方面, 制定针 对研究生出国交流的科研成果考核机制, 避免发生为了增 加海外经历而参与的 “出国旅游” 式交流, 提升研究生出 国交流的效果; 促使导师注重研究生出国交流的质量和科 研成效, 对学生盲目的出国项目能够给予及时纠正和引导。

我们要认识到, 扩大研究生出国交流数量是研究生教 育国际化的一种途径, 但并非唯一途径, 加强国际合作必 须以提升研究生教育的质量和研究生的国际素养为最终 目标, 决不能为了追求参与国际交流的数量而放任学生不 加选择地参与出国交流项目, 这实际上是人力、物力的浪 费, 而不是国际化提升的表现。对这一问题的正确认识, 将促使高校管理人员和教师在推动研究生教育国际化工 作中做出更为积极的努力。比如, 如何在本土环境下增强 研究生的国际化意识, 提升其国际交流能力和国际学术前 沿素养; 再比如, 开辟多种国际化培养途径, 针对经管类 研究生, 可以利用专业特点, 采用与跨国企业联合培养的 产学研结合模式, 或与国外大学合作推行交换生项目模式, 在培育学生的科研热情及创新精神过程中, 推进国际化进 程。

(3) 提升来华外国留学研究生的生源质量。

通过对留学生和教师的访谈, 我们注意到来华留学生 大多数是得到我国政府资助, 而且资助的额度从2015年起 有较大幅度的上升, 每位留学生每年可获得中国政府 36000 元的奖学金; 相比之下, 本国研究生需要交纳每年 8000 元学费和 900 元住宿费, 生活费大约 2000 元每个月, 一年共计 34000 元左右。由此可见, 留学生的资助标准还 是较高的。这对国家是一笔不小的支出, 尤其是考虑中国 学生到欧美国家留学获得留学国家的奖学金的难度非常 大, 大部分优秀的中国学生也是通过获得中国留学基金委
的资助或是自费出国留学的。以美国为例, 在美国的国际 学生学费高且不能享受美国政府的补贴, 据业内人士估算, 高昂的学费为美国经济做出了极大的贡献, 在2014/2015 年度, 留学生给美国带来308亿美元 (保守估计折合人民币 将近1500亿) 的经济收入, 很大程度上弥补了美国财政的 空虚。这与中国的国际学生消耗中国政府的资金而不是为 中国创收形成鲜明对比。

我们还注意到学院几乎没有来自英语国家的留学生, 他们的英文水平一般, 中文能力也很差或较差, 学术素养 普遍偏低, 在进行课程考核及毕业答辩时往往需要降低标 准, 非但没能由于优秀的外国留学生的加入, 为国内研究 生教育带来良好风气, 而且产生不良影响。从留学生的学 习诉求来看, 他们希望在中国学习阶段, 快速提升其中文 能力, 但从实际情况来看, 效果并不理想, 几位留学生反 映, 在相当大程度上, 他们需要通过自学提升中文能力。 从中国角度来看, 希冀来华留学生日后扩大中文的影响, 至少目前来看, 效果也很一般。同时, 由于来华留学生人 数的快速增加, 给大学的管理带来一系列问题, 增加了管 理成本。对于上述问题, 国内许多高校都面临相同情况, 目前大多数中国大学还很难吸引发达国家的优秀学生, 这 既与我国在国际上的综合实力和开放度有关, 也与大学自 身的国际知名度有关。

尽管一所大学的外国留学生数量在一定程度上标志 着其教育国际化的程度, 但是外国留学生的质量才能真正 反映其国际化水平。在目前阶段我国仍很难吸引到高水平 外国留学生的情况下, 更应该加大吸引外国留学生的政策 力度、而不是相反。因为吸引外国留学生到本国学习, 是 除了选送本国学生出国留学之外的另一项重要的研究生 教育国际化方式, 在这方面最成功的就是美国的研究生教 育, 据美国留学大数据《2015美国门户开放报告》公布的 数据表明, 2014-2015学年留美人数为 974926 人, 美国吸 纳了全球 450 万高校学生, 稳居世界第一, 几乎是第二大留 学目的地国家英国的两倍。更为重要的是, 美国吸引到本 国的外国留学生, 都需要经过严格的笁选机制, 包括竞争 激烈的英语能力考试、严格的在母国上一阶段的学业成绩 要求, 以及推荐信和其他各种证明材料等的严格把关, 只 有那些各国最为优秀的学生才能得到去美国留学的机会。 我国现阶段在吸引外国留学生的政策上, 除了加大吸引外 国留学生的力度, 同时更要提升录取留学生的条件, 宁可 少招甚至不招, 不能轻易降低对留学生的招收条件, 更不 能为了所谓 “国际化” 而不加选择地盲目扩大留学生数 量。

从根本上来看, 我们需要改进自身的办学水平, 提高 国际声誉, 努力吸引一些高水平的外国留学生, 进而提高 外国留学研究生在我国的学术贡献。随着中国在国际上的 综合实力的加强和高校自身国际化进程的加快, 相信我国 越来越多的高校将会在外国留学生的挑选中, 制定相对较 严的标准来提高本校外国留学生的质量。

\section{5. 结论}

通过对北京理工大学经管类研究生和教师的调研, 我 们发现当前研究生教育国际化中存在的一些问题, 包括, 
研究生全英文课程体系尚待建设、研究生 “追风式” 盲目 出国, 以及由我国政府资助的来华留学生素质较低等问题。 从根本上分析上述问题的原因, 我们认为, 由于近年来国 家推行研究生扩招措施, 许多高校在研究生培养上出现了 重规模、轻质量的现象, 这一现象反映在研究生教育国际 化方面最为直接的表现就是, 注重推进研究生教育国际化 的加快发展, 而疏忽了提升研究生教育国际化的质量。这 种要速度不要质量的国际化, 失去了通过国际化提升研究 生培养质量和吸引国外优秀人才形成外溢效应的意义和 目标。我们认为, 研究生扩招和推进研究生教育国际化这 两个政策措施的确存在一定的内在冲突和矛盾, 这是因为 推行研究生教育国际化对教师和研究生的英文能力和科 研能力提出了更高的要求; 而研究生扩招措施的实行, 使 得研究生数量迅速增长的背后, 高校的教育资源并没有同 步增加, 不少学生在就读期间没有得到导师的充分指导, 缺乏必要的学术引导和科研能力训练, 从生源和培养过程 看, 导致研究生质量的下降。为扩大国际化规模以国家巨 额资金花费为代价吸引来的外国留学生质量不高, 非但不 能为导师和国内学生带来科研帮助和示范效应, 反而占用 导师资源, 拉低研究生培养标准, 对本国学生起到相反的 示范效果。

从本项立足北京理工大学管理与经济学院对研究生 教育国际化的调研来看, 当前我国研究生教育国际化工作 的重点不是继续加快推进研究生教育国际化的速度, 而是 应适当放低速度, 将精力放到提升研究生教育国际化的质 量上来, 不能为了国际化而国际化, 而忘却了国际化的目 的和根本所在。研究生教育国际化已是大势所趋, 它是在 全球经济一体化的背景下, 教育顺应时代需要的一种发展 趋势。研究生教育的开放性, 决定了研究生教育需要对外 交流与合作, 借鉴和引进各个国家在研究生培养上的优势。 我们不可能等到研究生培养质量提升后, 再推行研究生教 育的国际化。实际上, 通过制定一系列保证研究生培养质 量和提升研究生教育国际化效果的政策, 可以使研究生培 养质量的提升和研究生教育国际化的推行相辅相成, 通过 国际交流使学生开阔学术眼界、了解国际前沿科技, 把握 研究方向和主流, 获取专业领域的国际前沿知识, 提升科 研能力。高校在推进国际化的进程中, 需进一步提升研究 生的培养质量。通过制定相应政策措施, 对研究生质量进 行把控。虽然国外高校的淘汰制在现阶段可能不适合中国 国情, 但随着不断改进培养方式, 制定并实施延迟毕业等 变通措施, 可以在一定程度上起到提升研究生培养质量的 积极作用。

\section{致谢}

本文为北京理工大学教学教育改革课题《加快推荐我 国研究生教育国际化进程的研究》的阶段性成果之一。

\section{参考文献}

[1] 徐岗, 许迈进中韩研究生教育国际化比较研究 [J]. 比较教 育研究，2003（11）：52-57。

[2] 罗尧成, 束义明. 我国高校研究生教育国际化现状分析及 对策建议 [J]. 学位与研究生教育, 2009 (11) : 58-63。

[3] 李素琴, 间效鹏. 研究生教育国际化初探 [J]. 中国高教研 究, 2003 (11)：59-61。

[4] 王根顺, 张增艳. 我国高校研究生教育国际化的现状分析与 对策研究 [J]. 内蒙古师范大学学报 (教育科学版), 2010 (3)。

[5] 林伟连, 徐为民. 我国研究生教育国际化实践途径探微 [J]. 学位与研究生教育, 2004（6）。

[6] 编写组. 中国学位与研究生教育发展战略报告 [J]. 学位与 研究生教育, 2002（6）：1-21。

[7] 罗英姿, 李芹, 韩纪琴, 曲福田. 高校研究生教育国际化评 价指标体系构建初探 [J]. 学术探索, 2009 (11):64-69。

[8] 张卓, 李璐, 王敏. 经管类研究生国际化培养方案研究 [J]. 江苏科技信息，2015(4):35-38。

[9] 赵伟. 对推进我国研究生教育国际化的思考 [J]. 学位与研 究生教育, 2003 (10) : 10-13。

[10] 岳锋利. 推进我国研究生教育国际化的措施及问题 [J]. 理论与实践, 2005(5):86-87。

[11] 邢玉升. 我国高校经管类研究生培养的现状与问题 [J]. 人力资源管理，2015(11):156-157。

[12] 杨吴. 我国研究生教育国际化问题及对策初探 [J]. 长春教 育学院学报, 2013 (17)。

[13] 刘文, 徐荣丽, 柇晓志. 西方经济学专业研究生教育国际化 研究 [J]. 经济师, 2014 (9) : 258 260。

[14] 孙文远, 邹礼梦. 经济贸易类研究生教育国际化的探究- 以南京审计学院为例 $[J]$. 教育与教学研究, 2016（2）。

[15] 初旭新, 宗刚. 我国研究生教育国际化培养的现状与对策 $[J]$. 研究生教育研究, 2015 (10)。

[16] 刘宗明, 高新伟. 欧美国家研究生教育国际化的进展、特征 及其启示 $[J]$. 中国石油大学学报 (社会科学版), 2016(1): 107 112。

[17] 陈怡, 孙文远. 全球化背景下研究生教育国际化问题研究 $[J]$. 研究生教育研究, 2016 (1) :25 30。 